\title{
Avaliação da opção de troca de combustível no carro brasileiro flex: um estudo por região geográfica usando teoria de opções reais e simulação estocástica
}

\author{
Carlos Patricio Samanez ${ }^{a *}$, Léo da Rocha Ferreira ${ }^{b}$, Carolina Caldas do Nascimento ${ }^{c}$ \\ a*cps@puc-rio.br, PUC-Rio, Brasil \\ bleorocha@uerj.br, UERJ, Brasil \\ ccaldas_carolina@hotmail.com, PUC-Rio, Brasil
}

\begin{abstract}
Resumo
A introdução do carro flex-fuel no mercado brasileiro em 2003 mudou a forma de decisão do consumidor. Se antes era necessário escolher o combustível pelo tipo de veículo, movido somente a gasolina ou somente a álcool, hoje é possível escolher um tipo de carro com duas opções de combustível. Essa flexibilidade gera uma vantagem econômica para o seu proprietário, mas qual o benefício financeiro de um carro flex-fuel em comparação a um carro movido somente a gasolina? Geograficamente, onde se localiza o proprietário que se beneficia mais dessa flexibilidade? Este estudo aplica a teoria de opções reais e a simulação estocástica para valorar a opção do carro flex para as cinco regiões geográficas do Brasil. Considera-se que os preços dos insumos são estocásticos e seguem o movimento de reversão à média. A previsão dos preços e o valor da opção são gerados através da simulação de Monte Carlo. Os resultados indicam que a opção de escolher o combustível mais barato adiciona considerável valor para o proprietário do carro flex em todas as regiões e modelos de carro considerados, sendo a região Sudeste a mais beneficiada pela opção flex.
\end{abstract}

Palavras-chave

Avaliação de opções reais. Modelos de apreçamento de commodities. Carro bicombustível. Simulação estocástica.

\section{Introdução}

0 fim do petróleo barato, com a formação do cartel dos países exportadores de petróleo depois de 1973, levou a economia mundial a profundas transformações. Os importadores de petróleo, especialmente os países em desenvolvimento, foram os mais afetados, dada a dificuldade de se adaptarem à nova realidade. No Brasil, o desenvolvimento e uso do etanol pelo Programa Nacional do Álcool (Proálcool) foi uma das muitas formas de se tratar com a crise do petróleo.

Em um estudo da viabilidade econômica e social da indústria do etanol no Brasil feita por Serôa da Motta e Ferreira (1988), mostraram os autores 30 anos atrás que a produção de etanol iria se tornar uma realidade em vista do considerável aumento da produtividade da indústria e do aumento dos preços do petróleo, fatores que viraram uma realidade a partir do final dos anos 90 . Os autores mencionam que, considerando que os investimentos já efetuados na indústria de etanol podem ser considerados como custos afundados, a indústria torna-se perfeitamente viável até com preços do petróleio na faixa de US\$ 15-US\$ 20.

Nesse contexto, o automóvel flex-fuel foi lançado no mercado brasileiro em março de 2003, e seu desenvolvimento e popularização se deram principalmente pela experiência brasileira gerada durante três décadas de exploração do etanol. Com essa nova tecnologia, o consumidor passou a escolher o combustível no momento do abastecimento, e não mais no momento da compra do veículo. 0 carro flex é capaz de funcionar com gasolina C (com uma proporção de etanol anidro), etanol hidratado ou qualquer mistura desses dois combustíveis em qualquer proporção. Desde seu lançamento suas vendas só 
crescem, no ano de 2010 já foram responsáveis por mais de $85 \%$ dos veículos comercializados no Brasil (ASSOCIAÇÃO..., 2010).

A flexibilidade proporcionada por esse automóvel é vantajosa para o seu proprietário, pois ele passa a escolher o combustível mais barato em cada abastecimento. Essa opção de escolha pode ser entendida como uma opção de troca de insumo.

Os métodos de fluxos de caixa descontados e seu principal indicador, o valor presente líquido (VPL), vêm sendo usados durante muito tempo como critérios para a tomada de decisões de investimento. Porém, esses métodos não valoram as flexibilidades implícitas nos projetos de investimento, as que de fato precisam ser mensuradas e incorporadas na avaliação. Tal como afirma Trigeorgis (1996), as flexibilidades gerenciais podem ser vistas como um leque de opções reais que agregam valor ao projeto, e esse valor é quantificado na abordagem conhecida como opções reais. Um dos pontos principais na aplicação da abordagem das opções reais é a correta definição do processo estocástico que modela as previsões de preços dos ativos ou commodities.

Em Bessembinder et al. (1995), para os preços de commodities agrícolas e preço spot do petróleo, os autores constataram evidências estatísticas de reversão à média de longo prazo. Para o preço de metais, no entanto, o grau de reversão encontrado foi substancialmente menor, mas não rejeitado estatisticamente. Por outro lado, para o preço de ativos financeiros, foi detectada uma fraca evidência de reversão à média.

Em Kulatilaka (1993), usando a abordagem das opções reais, o autor calcula o valor de uma caldeira que pode usar como combustível óleo residual ou gás. 0 autor defende a utilização do movimento de reversão à média (MRM) na modelagem dos preços dos insumos em caldeiras bicombustíveis, e conclui que uma volatilidade maior nos preços relativos aumenta o valor da flexibilidade, ou seja, da opção real de troca. No entanto, o autor menciona que o aumento da presença dessa tecnologia flexível (caldeiras bicombustíveis) diminui a volatilidade das mudanças dos preços relativos (há um aumento de correlação entre os preços), reduzindo potencialmente o valor futuro da flexibilidade.

Schwartz (1997) valorou projetos de exploração de recursos naturais usando três diferentes modelos que consideram a natureza de reversão à média do preço spot das commodities petróleo e cobre. 0 primeiro modelo por ele utilizado é o de um fator, considerando um processo de Ornstein-Uhlenbeck, o segundo é uma variação do modelo de dois fatores de Gibson e Schwartz (1990) e, o terceiro, uma versão estendida de Gibson e Schwartz com a inclusão de um novo fator estocástico. 0 autor destaca a importância de considerar o MRM para os preços de commodities na valoração de projetos.

A literatura disponível apresenta poucos trabalhos que valoram a opção do carro flex brasileiro. Os mais importantes e conhecidos são o de Camargo Jr. et al. (2011) e o de Bastian-Pinto, Brandão e Alves (2008).

Camargo Jr. et al. (2011) adotaram o movimento geométrico browniano (MGB) para modelar e simular as previsões de preços na valoração da opção de troca de insumo do veículo flex-fuel. Além de usar um processo como o MGB, que não é o mais apropriado na modelagem de preços de commodities como o etanol e a gasolina, o estudo foi realizado para o país como um todo, ignorando as diferenças na demanda e na formação de preços que existem nas diversas regiões do Brasil. Devido ao processo estocástico usado, os resultados obtidos são seriamente afetados, pois o uso de um MGB com drift positivo acarreta a obtenção de preços estimados que crescem ao longo do período de projeção. Igualmente, o valor da opção é muito mais afetado pela volatilidade dos preços, pois no MGB a variância cresce indeterminadamente com o tempo, contrário ao MRM em que seu crescimento é limitado pela tendência de reversão à média de longo prazo. Os autores usaram dados dos preços dos combustíveis no período de julho de 2001 a dezembro de 2009. No artigo, a correlação entre os preços do etanol e da gasolina, que é um fator que afeta o valor da flexibilidade, não teve a sua inclusão explícita nas equações de simulação. No presente trabalho, na seção 5.2, a correlação entre os preços será incorporada nas equações de simulação por meio da decomposição de Cholesky.

Bastian-Pinto, Brandão e Alves (2008) analisaram o valor da opção do automóvel flex-fuel utilizando dois processos estocásticos: o MGB e o MRM. Os autores concluem que o valor da opção é significativo pelos dois processos estocásticos, sendo o valor da opção de troca de combustível 24,4\% maior para o MGB em relação ao MRM. Tal como o artigo de Camargo Jr. et al. (2011), o estudo de Bastian-Pinto, Brandão e Alves (2008) desconsiderou também a regionalização, fazendo uma análise para o país com um todo, e não fez inclusão explícita da correlação entre os preços nas equações de simulação. 0 artigo usou séries de preços dos combustíveis no período de julho de 2001 a outubro de 2006.

No Brasil, a demanda e a formação dos preços dos combustíveis é muito diferenciada por região geográfica, devido aos diferentes custos da logística de distribuição, margens e taxas de ICMS. No presente estudo, diferentemente aos citados artigos, a regionalização será considerada de modo 
a estimar de modo mais apropriado e realista os preços simulados e o valor da opção embutida no automóvel flex-fuel em cada região geográfica do país. Diferente a esses artigos, neste estudo, nas equações de simulação dos preços dos combustíveis, será explicitamente incorporada a correlação entre os preços do etanol e da gasolina, o que será feito por meio da decomposição de Cholesky, gerando um novo fator estocástico que será associado a um dos fatores de risco (seção 5.2). Neste trabalho, as séries de preços usadas correspondem ao período de julho de 2001 a setembro de 2011, refletindo, de modo mais apropriado em relação a trabalhos anteriores, a mudança na relação do preço etanol-gasolina ocorrida no último biênio, o que de fato afetou o valor da opção embutida no veículo flex-fuel.

\subsection{O problema e os objetivos da pesquisa}

Para o consumidor que possui um carro flex-fuel, a incerteza associada aos preços dos combustíveis the proporciona uma vantagem se considerada a opção de troca entre etanol e gasolina. Defensores dessa nova tecnologia argumentam que essa é a maior vantagem de possuir esse tipo de automóvel, além da sensação de segurança associada a essa possibilidade de troca. Mas qual é o custo-benefício do carro flex-fuel em comparação a um carro movido somente a gasolina? A opção de troca de combustível é vantajosa para o proprietário? Regionalmente, no Brasil, onde se localiza o proprietário que se beneficia mais dessa flexibilidade? Neste estudo é aplicada a abordagem das opções reais e a simulação estocástica para responder essas questões.

Diferentemente aos trabalhos anteriormente citados, neste estudo serão consideradas as particularidades de preços em cada região do Brasil, determinando em qual das regiões geográficas encontra-se o consumidor que possui maiores benefícios da flexibilidade dada pelo automóvel flex-fuel. 0 estudo contribui para a difusão de estudos de opções reais aplicadas a motores bicombustíveis, demonstrando suas vantagens econômicas sobre os motores movidos exclusivamente a combustíveis fósseis.

0 presente artigo divide-se em cinco seções, sendo a primeira uma breve introdução onde são apresentados o problema e o objetivo do trabalho e analisado o estado da arte sobre o assunto. Na seção 2 é analisada a nova geração de carros bicombustível no Brasil. Também são apresentadas a formação de preços do etanol e da gasolina e a competição e paridade entre os preços desses combustíveis nas diversas regiões brasileiras. Na seção 3 são detalhados os dados usados na modelagem e simulações. Na seção 4 são descritos alguns processos estocásticos e as metodologias para a escolha do processo estocástico apropriado, além de apresentadas as equações que discretizam o MRM usado nas simulações e previsões dos preços. Na seção 5 são feitas as simulações estocásticas dos preços e valorada a opção de troca de combustível. Finalmente, na seção 6, são apresentadas as conclusões e perspectivas futuras do assunto tratado neste artigo.

\section{A nova geração de carros bicombustíveis no Brasil}

A tecnologia flex-fuel surgiu nos EUA nas décadas de 1980 e 1990 quando o governo criou legislação obrigando à adaptação da frota para combustíveis alternativos. 0 motor convencional a gasolina foi transformado em um motor "inteligente", capaz de fazer um ajuste automático de sua operação para responder adequadamente à mistura de etanol com gasolina. Nos EUA, a mistura de etanol foi limitada em $85 \%$ para facilitar a partida do motor em condições de frio, comum em regiões dos EUA. Isso tornou a concepção norte-americana mais simples e limitada comparada com a brasileira, pois não possui um sistema auxiliar de partida a frio que permita o uso do etanol puro. No Brasil, a experiência de produzir automóveis movidos exclusivamente a etanol possibilitou o desenvolvimento de uma tecnologia flex-fuel superior à norte-americana, com melhor desempenho e economia, além da possibilidade de utilizar $100 \%$ de etanol.

0 automóvel flex-fuel foi lançado no mercado brasileiro em março de 2003, pela Volkswagen, através do modelo Gol Total Flex, que podia funcionar com gasolina C (com uma porcentagem de etanol anidro), etanol hidratado ou qualquer mistura desses dois combustíveis em qualquer proporção no mesmo tanque. 0 carro flex possibilitou que o etanol pudesse competir com a gasolina em todo o Brasil, permitindo ao consumidor a opção de migrar para gasolina caso o preço do litro de etanol ultrapasse 70\% do preço do litro da gasolina (valor sugerido pelo Centro de Estudos Avançados em Economia Aplicada CEPEA-USP (2011)).

Desde seu lançamento em 2003, os veículos flex apresentam um constante crescimento em suas vendas. Em 2005 já representavam aproximadamente a metade das vendas, superando a partir de 2006 os carros a gasolina e diesel. Em 2010, mais de 86\% dos carros leves comercializados no Brasil possuíam a tecnologia flex. 0 sucesso desses veículos trouxe benefícios não só para os consumidores, mas também para a economia brasileira, tanto na geração de empregos quanto na economia dos gastos com combustíveis fósseis e na melhoria do ar das cidades. A inserção dos automóveis 
flex no mercado representou para as montadoras economia no desenvolvimento de produtos e, para os produtores de etanol, maior flexibilidade na oferta do combustível em função das variações de safra e oportunidades no mercado de açúcar.

\subsection{A formação dos preços dos combustiveis no Brasil}

Desde 1938 até recentemente, os preços dos combustíveis no Brasil foram estabelecidos pelo governo, com um complexo sistema de subsídios. Com a Lei no 9.478, de 6 de Agosto de 1997 (Lei do Petróleo) (BRASIL, 2013), se procurou caminhar para a desregulamentação, estabelecendo preços livres, importações liberadas para os derivados e subsídios extintos, exceto quando previamente aprovados pelo Congresso Nacional. No entanto, na realidade, os preços dos combustíveis no Brasil dependem do que acontece com a cotação do real e dos preços do petróleo e derivados no mercado internacional. 0 que se vê, na prática, é a dificuldade do governo em repassar os aumentos dos preços internacionais, utilizando os preços dos combustíveis para executar políticas públicas e objetivos de política fiscal e monetária.

0 órgão brasileiro regulador desse mercado é a Agência Nacional do Petróleo, Gás Natural e Biocombustíveis (ANP), que possui entre suas atribuições o estabelecimento de regras e a fiscalização das indústrias reguladas.

0 preço dos combustíveis na bomba pode ser dividido basicamente em quatro componentes: preço de realização, impostos, logística e margem. 0 primeiro é o preço de venda sem impostos e fretes na usina/refinaria às distribuidoras de combustíveis. 0 segundo é composto pelo PIS/Pasep, Cofins, ICMS e a Cide. Já a logística é composta pelo frete da usina/ refinaria ao distribuidor e do distribuidor ao posto de revenda do combustível. E, por último, a margem, que é formada por uma parcela do distribuidor e outra do revendedor.

Deve-se dar especial destaque ao Imposto sobre Circulação de Mercadorias e Serviços, o ICMS, que não é fixo nem por estado nem por tipo de combustível. 0 estado de São Paulo, por exemplo, tributa o etanol em 12\% e a gasolina em 25\%, o mesmo não ocorre no estado do Paraná, que tributa o biocombustível em 18\% e o fóssil em 28\%, já no estado do Pará a impostação sobre o etanol chega a ser até mesmo de $30 \%$.

Outros fatores podem ser destacados como determinantes nas diferenças dos preços dos combustíveis ao consumidor. Dentre esses temos o tamanho do mercado e a variação do custo da logística de acordo com a distância do estado produtor ao consumidor final.

\subsection{Paridade entre os combustíveis nas regiões brasileiras}

A Tabela 1 apresenta, no período de 2003 a 2010, para as diversas regiões geográficas do Brasil, a relação entre os preços ao consumidor do etanol hidratado e da gasolina C. Seus valores foram gerados considerando as médias anuais dos preços, deflacionados (base julho-2001) pelo índice geral de preços IGP-Di-FGV.

Como pode ser observado na Tabela 1 , a região Norte (N) foi a que apresentou a paridade mais desfavorável para o consumidor de etanol em todo o período analisado. 0 que pode ser explicado pela distância de seus estados aos centros produtores. A região Sudeste (SE) é a maior produtora e consumidora nacional de etanol. A sua situação favorável na paridade de preços pode ser explicada não somente pelo tamanho do seu mercado consumidor, mas também pela sua infraestrutura logística, pela existência de maior concorrência entre as distribuidoras e por margens de lucro relativamente pequenas, dado o grande volume de venda e alta concorrência. A região Centro-Oeste (CO), assim como a região Sudeste, possui o mercado consumidor muito próximo da produção. Além disso, sua produção é muito maior que o seu consumo, o que lhe atribui um enorme potencial de exportação. 0 grande volume de produção na região Sudeste pode ser visto como mais um fator que favorece a paridade entre o preço do etanol hidratado e o da gasolina. Por fim, a região Sul (S) possui o terceiro estado, o Paraná, com maior produção nacional de etanol hidratado na safra de 2008/2009. No entanto, sua oferta não é suficiente para atender toda a demanda de sua região. Esse

Tabela 1. Paridade média anual dos preços ao consumidor do etanol e da gasolina.

\begin{tabular}{lccccccccc}
\hline \multicolumn{1}{c}{ Região } & 2003 & 2004 & 2005 & 2006 & 2007 & 2008 & 2009 & 2010 \\
\hline Nordeste (NE) & 0,73 & 0,67 & 0,70 & 0,71 & 0,65 & 0,67 & 0,67 & 0,71 \\
Norte (N) & 0,80 & 0,73 & 0,73 & 0,80 & 0,73 & 0,71 & 0,70 & 0,74 \\
Centro-Oeste (CO) & 0,68 & 0,63 & 0,64 & 0,68 & 0,60 & 0,63 & 0,62 & 0,66 \\
Sudeste (SE) & 0,61 & 0,54 & 0,54 & 0,60 & 0,54 & 0,54 & 0,56 & 0,62 \\
Sul (S) & 0,65 & 0,60 & 0,62 & 0,68 & 0,61 & 0,61 & 0,62 & 0,67 \\
\hline
\end{tabular}

Fonte: elaboração própria. 
ponto, no entanto, não tornou essa região menos atraente para o consumo de etanol durante o período analisado, se considerada a paridade média anual da região.

\section{Dados usados na modelagem e simulações}

Neste trabalho foram utilizadas as séries históricas mensais dos preços ao consumidor do etanol hidratado e da gasolina por região geográfica do Brasil, no período de julho de 2001 a setembro de 2011, obtidas através do site da Agência Nacional do Petróleo - ANP (2011), contendo 123 observações para cada região e tipo de combustível. Esses valores são dados em reais por litro e contemplam o preço de realização de cada combustível, os fretes, os impostos federais e estaduais, as contribuições e as margens de lucro dos postos de combustíveis. Essa série foi deflacionada pelo índice geral de preços, IGP-DI, fornecido pela Fundação Getulio Vargas, tendo como mês e ano de referência julho de 2001.

Os resultados para todas as regiões das séries deflacionadas de preços para o etanol e gasolina podem ser vistos nas Figuras 1 e 2, respectivamente. Já na Figura 3 pode ser observado para a região Sudeste o preço do etanol ajustado a 1/70 (valor corrigido de acordo com CEPEA-USP (CENTRO..., 2011)) quando comparado à gasolina. Pode-se analisar nessas figuras que os preços deflacionados de ambos os combustíveis flutuam consideravelmente em torno de suas médias até 2005 , quando há um grande salto tanto para o etanol quanto para a gasolina. Após essa data, os preços retornam para níveis não muito

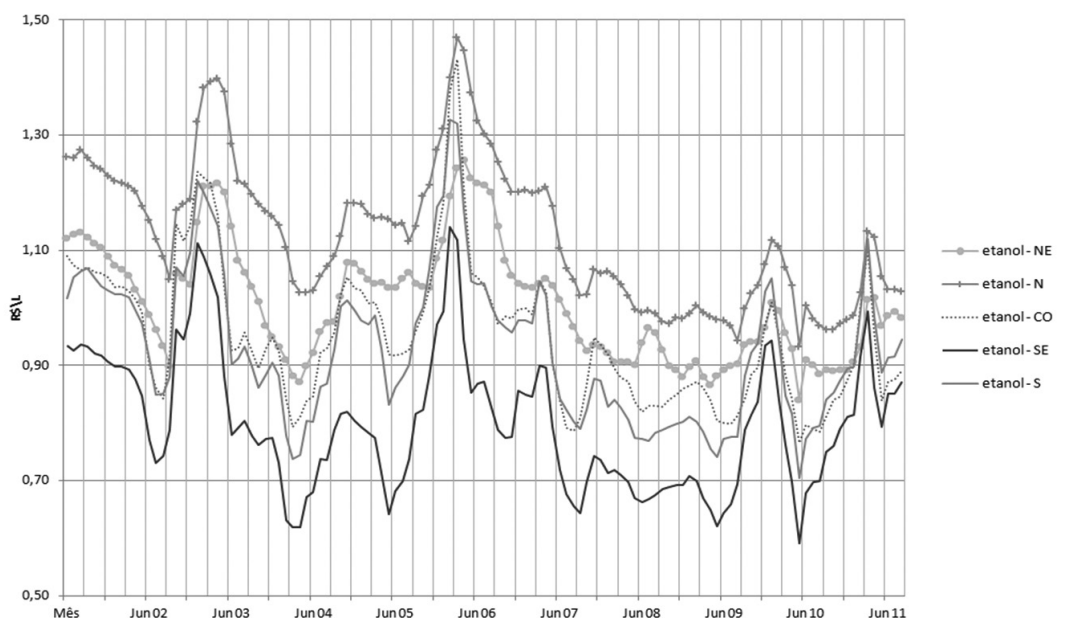

Figura 1. Preço médio do etanol deflacionado pelo 1GP-Dl por região geográfica do Brasil, base jul-2001.

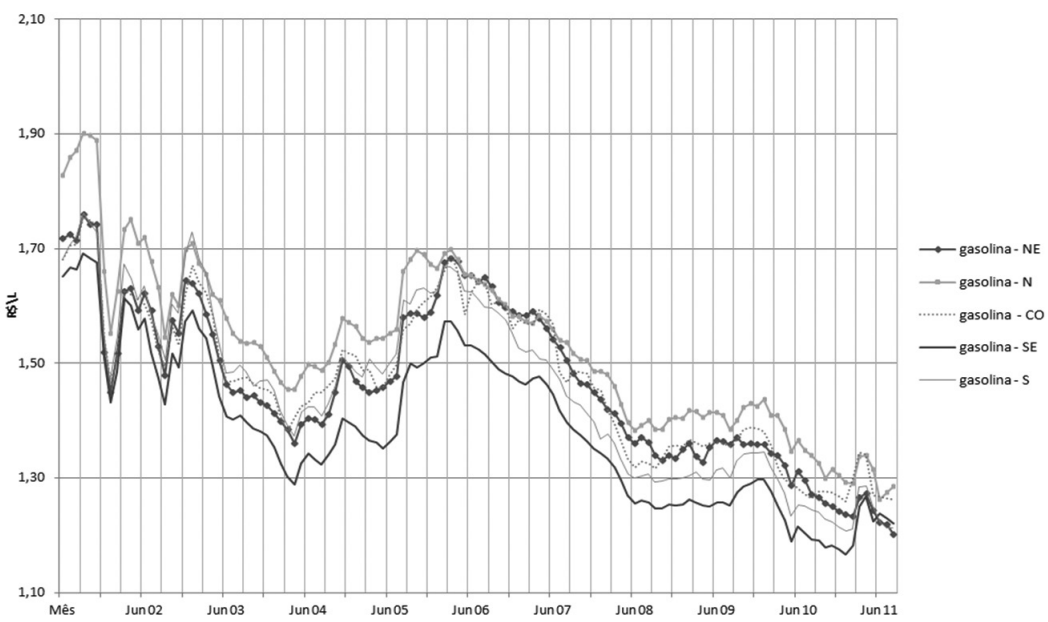

Figura 2. Preço médio da gasolina deflacionado pelo 1GP-Dl por região geográfica do Brasil, base jul-2001. 


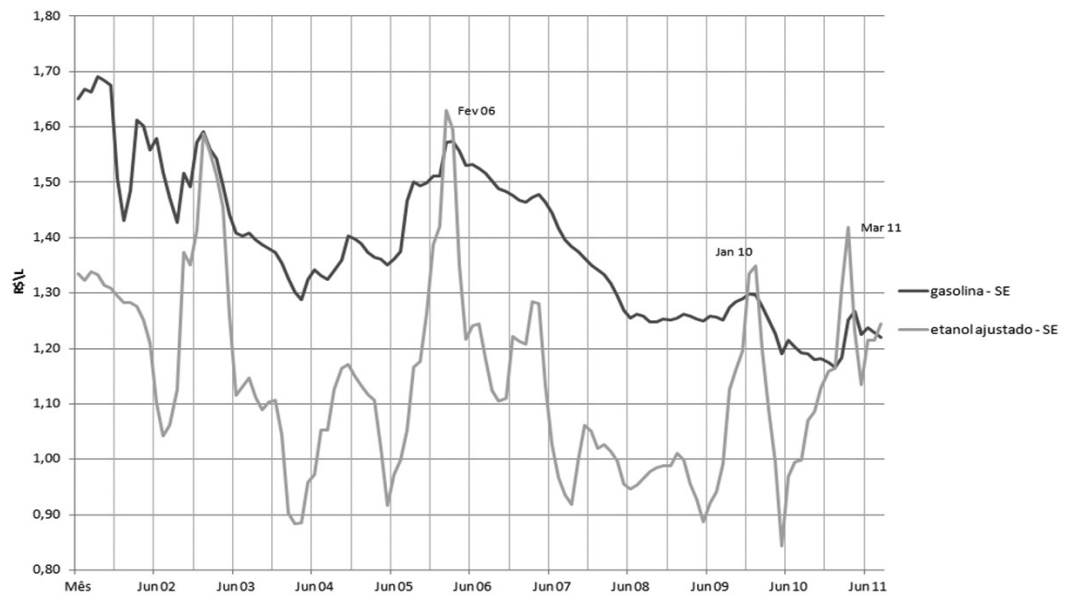

Figura 3. Evolução dos preços do etanol ajustado e gasolina na região Sudeste, base jul-2001.

abaixo dos anos anteriores. Esse comportamento, em torno da média, nos sugere a aplicação do MRM na modelagem dos preços. No entanto, não só a análise gráfica deve ser realizada para a determinação desse modelo, testes estatísticos também devem ser considerados, tal como será visto e analisado mais adiante neste artigo. As séries de preços deflacionados serão utilizadas neste estudo para determinar os parâmetros do processo estocástico que permite a simulação dos preços dos combustíveis.

\section{A abordagem de opções reais e os processos estocásticos aplicados na modelagem dos preços dos combustíveis}

Tal como mencionado anteriormente, os métodos de fluxos de caixa descontados têm sérias limitações, pois não consideram o valor das opções embutidas nas propostas de investimento. Segundo Trigeorgis (1996), o acréscimo trazido ao valor de um projeto pelas flexibilidades e opções embutidas é refletido no chamado VPL expandido, que é composto pelo VPL tradicional mais o valor das opções operacionais e estratégicas do projeto. A ideia é adicionar o valor das opções, caso contrário a alternativa de investimento estaria sendo subavaliada.

Neste estudo, o tipo de opção a ser modelada é a de troca de insumos (Switch Input). Para este tipo de opção, as ações gerenciais são tomadas devido à variação de natureza estocástica dos preços dos insumos, de forma que a escolha resulte no menor custo e/ou na maior lucratividade para o produtor/ consumidor de determinado produto ou insumo.

$\mathrm{Na}$ opção associada ao carro flex, os inputs disponíveis são os dois tipos de combustíveis, etanol e gasolina. Essa opção possibilita alterar sem custo o mix de combustíveis de acordo com o comportamento dos preços de mercado. 0 cálculo correto do valor dessa opção depende da definição do processo estocástico capaz de retratar a incerteza dos preços futuros dos insumos, de modo que esses preços possam ser simulados.

\subsection{Processos estocásticos aplicados na modelagem de opções reais}

Um processo estocástico descreve o comportamento de uma variável cujas mudanças são incertas ao logo do tempo, ou seja, é um processo aleatório em função do tempo. Os processos estocásticos podem ser classificados como de tempo contínuo ou discreto, se contínuo as mudanças podem ocorrer em qualquer tempo, caso contrário elas só acontecem em pontos fixos no tempo.

$\mathrm{Na}$ abordagem das opções reais, de modo a modelar os preços visando valorar as opções embutidas nas alternativas de investimento, geralmente são três os principais processos estocásticos usados: o movimento geométrico browniano (MGB), o movimento de reversão à média (MRM) e o MRM com saltos de Poisson. A ideia por trás do MRM pode ser entendida considerando que, em um mercado competitivo, se o preço da commodity estiver muito abaixo da média de longo prazo, a oferta diminui forçando os preços para cima devido à escassez do produto no mercado, e o mesmo se entende no sentido oposto. De tudo isso se pode concluir que a série de preços das commodities tem uma tendência natural de reverter ao seu preço médio de longo prazo, ou seja, à média de equilíbrio de mercado, por mais que esse processo de reversão seja lento. 


\subsubsection{Processos de Wiener}

0 processo de Wiener, também conhecido como movimento browniano, é um processo markoviano em tempo contínuo. Por ser um processo de Markov e ter incrementos independentes, o valor corrente da variável independe da trajetória dos preços no passado. Os incrementos possuem distribuição normal com parâmetros que dependem somente do intervalo de tempo (incrementos estacionários).

Caso $\mathrm{z}(\mathrm{t})$ seja um processo de Wiener no tempo $t$, então, qualquer variação, $\Delta z$, em $z$, em um intervalo de tempo, $\Delta f$, deve satisfazer as seguintes condições: a) a relação entre $\Delta z$ e $\Delta f$ deve ser dada por: $\Delta z=\varepsilon(t) \sqrt{\Delta t}$, onde $\varepsilon(t) \sim N(0,1) ;$ b) a variável aleatória $\varepsilon(t)$ não possui correlação serial, ou seja, $E[\varepsilon(t), \varepsilon(s)]=0$ para $t \neq s$. Isso significa que os valores de $\Delta z$ para dois intervalos de tempo diferentes são independentes, dessa forma $z(t)$ segue um processo de Markov.

\subsubsection{Movimento geométrico browniano}

0 movimento geométrico browniano (MGB) é o mais popular na modelagem de ativos financeiros e reais, o que pode ser explicado pela simplicidade de aplicação e principalmente pela sua fácil compreensão. É um processo apropriado para variáveis que crescem exponencialmente a uma taxa média $\alpha$ e volatilidade proporcional ao nível da variável $X$.

No MGB, a equação estocástica para uma variável $X$ que varia no tempo é definido pela seguinte equação estocástica:

$d X=\alpha X d t+\sigma X d z$

onde $X=$ variável estocástica; $d X=$ variação instantânea de $X, \alpha=d r i f t$ (tendência) da variável estocástica; $d t=$ diferencial de tempo; $\sigma=$ volatilidade instantânea da variável estocástica; $d z=$ incremento ou diferencial de Wiener.

De acordo com Dixit e Pindyck (1994):

$$
\begin{aligned}
& d z(t)=\varepsilon(t) \sqrt{d t}, \text { onde } \varepsilon(t) \sim N(0,1) \\
& E(d z)=0 \\
& \operatorname{Var}(d z)=E\left[\left(d z^{2}\right)\right]-[E(d z)]^{2}=E\left[\left(d z^{2}\right)\right]=d t
\end{aligned}
$$

Conforme demonstram Dixit e Pindyck (1994), para uma variável $X(t)$ que segue um MGB e possui uma distribuição lognormal, a média e a variância são dadas por:

$$
E[X(t)]=X_{0} e^{\alpha t}
$$

$$
\operatorname{Var}[X(t)]=X_{0}^{2} e^{2 \alpha t}\left(e^{\alpha^{2} t}-1\right)
$$

\subsubsection{Movimento de reversão à média}

0 movimento de reversão à média (MRM) é um processo em tempo contínuo. 0 seu modelo mais simples, também conhecido como processo de um fator de Ornstein-Uhlenbeck ou movimento aritmético de reversão à média, é definido pela seguinte equação estocástica:

$d X=\eta(\bar{X}-X) d t+\sigma d z$

onde: $X=$ variável estocástica; $\eta=$ velocidade de reversão à média da variável estocástica; $\bar{X}=$ média de longo prazo da variável estocástica; $\sigma=$ volatilidade da variável estocástica; $d z=$ incremento ou diferencial de Wiener.

Geralmente, assume-se que os preços $(x)$ das commodities são distribuídos segundo uma distribuição lognormal. Dessa forma, se $x=\ln (x)$, então $x=e^{x} 0$ que mantém o preço da commodity sempre positivo por mais que o valor de $X$ possa ser negativo, pois não teria sentido, por exemplo, uma série de preços de commodities com valores negativos.

A distribuição condicional de $X$ no instante $T$ sob medida equivalente de martingale tem distribuição normal, com média e variância dados pelas Equações 5 e 6 a seguir (DIXIT; PINDYCK, 1994):

$E[X]=\bar{X}+\left(X_{0}-\bar{X}\right) e^{-\eta T}$

$\operatorname{Var}[X]=\left(1-e^{-2 \eta T}\right) \sigma^{2} / 2 \eta$

\section{Discretização do MRM}

Para realizar a simulação do processo estocástico e consequente estimação dos preços futuros, é preciso a equação de discretização, isto é, ter $X_{t}$ em função de $X_{t-1}$. A equação discretizada para a simulação real do MRM para um intervalo de tempo (Dt) é dada segundo Dias (2008) pela Equação 7 a seguir:

$$
X_{t}=X_{t-1} e^{-\eta \Delta t}+\bar{X}\left(1-e^{-\eta \Delta t}\right)+\sigma \sqrt{\frac{1-e^{-2 \eta \Delta t}}{2 \eta}} N(0,1)
$$

De acordo com Schwartz (1997), para que uma variável estocástica que segue um MRM do tipo $d X(t)=\eta[\bar{X}-X(t)] d t+\sigma d z(t)$ possa ser ajustada para um ambiente neutro ao risco, basta subtrair um prêmio de risco normalizado, $\pi / \eta$, da média de longo prazo, conforme a equação: $d X(t)=\eta\left(\left(\bar{X}-\frac{\pi}{\eta}\right)-X(t)\right) d t+\sigma d z(t)$. 
A Equação 8, mostrada a seguir, apresenta essa adaptação para uma simulação neutra ao risco do MRM:

$X_{\bar{l}} X_{t-1} e^{-\eta \Delta t}+\left[\bar{X}-\frac{\pi}{\eta}\right]\left(1-e^{-\eta \Delta t}\right)+\sigma \sqrt{\frac{1-e^{-2 \eta \Delta t}}{2 \eta}} N(0,1) \quad$ onde: $\pi=\mu-r$

\section{Estimação dos parâmetros do MRM}

Para que o MRM possa ser discretizado, é necessária a estimação dos parâmetros presentes na equação estocástica (4), ou seja, a volatilidade, a média de longo prazo e a velocidade de reversão. Para isso, é efetuada uma regressão linear sobre os dados históricos dos preços.

Como demonstrado em Bastian-Pinto, Brandão e Alves (2008), os preços que seguem um MRM podem ser descritos a partir da equação da média (Equação 5), conforme a Equação 9, mostrada a seguir:

$X_{t}=\bar{X}+\left(X_{t-1}-\bar{X}\right) e^{-\eta \Delta t}=\bar{X}\left(1-e^{-\eta \Delta t}\right)+X_{t-1} e^{-\eta \Delta t}$

Subtraindo $X_{t-1}$ de ambos os lados da Equação 9 e considerando o erro da regressão:

$X_{t}-X_{t-1}=\bar{X}\left(1-e^{-\eta \Delta t}\right)+X_{t-1}\left(e^{-\eta \Delta t}-1\right)+\varepsilon_{t}$ onde: $\varepsilon(t) \sim N\left(0, \sigma_{\varepsilon}^{2}\right)$

Considerando que $X_{t}=\ln \left(x_{t}\right)$ e $\bar{X}=\ln (\bar{x})$, a Equação 10 pode ser reescrita da seguinte forma:

$\ln \left(x_{t}\right)-\ln \left(x_{t-1}\right)=\ln (\bar{x})\left(1-e^{-\eta \Delta t}\right)+\ln \left(x_{t-1}\right)\left(e^{-\eta \Delta t}-1\right)+\varepsilon_{t}$

Finalmente, a equação de regressão é dada pela Equação 12:

$\ln \left(x_{t}\right)-\ln \left(x_{t-1}\right)=a+(b-1) \ln \left(x_{t-1}\right)+\varepsilon_{t}$

Através da Equação 12, regredindo o ln dos preços, podem ser estimados os coeficientes $a$ e $b$.

Por comparação das Equações 11 e 12 é possível obter os parâmetros necessários à discretização do MRM. Assim, conforme desenvolvido por Dixit e Pindyck (1994) e modificado por Dias (2008), as fórmulas para o cálculo da velocidade de reversão e a média de longo prazo são dadas, respectivamente, pelas Equações 13 e 14:

$$
\begin{aligned}
& b-1=e^{-\eta \Delta t}-1, \Rightarrow \eta=-\ln (b) / \Delta t \\
& 1-b=1-e^{-\eta \Delta t}, \quad \Rightarrow \bar{x}=\exp \left(-\frac{a}{(b-1)}\right)
\end{aligned}
$$

Também: $\quad a=\ln (\bar{x})\left(1-e^{-\eta \Delta t}\right)$
A determinação da volatilidade é obtida igualando a variância dos erros da regressão à Equação 6 da variância do MRM: $\sigma_{\varepsilon}^{2}=\left(1-e^{-2 \eta \Delta t}\right) \frac{\sigma^{2}}{2 \eta}$

Considerando que $b^{2}=e^{-2 \eta \Delta t}$ e substituindo a Equação 14 na equação anterior, temos que: $\sigma_{\varepsilon}^{2}=-\left(1-b^{2}\right)\left(\frac{\sigma^{2} \Delta t}{2 \ln (b)}\right)$

De onde se tem que : $\sigma=\sigma_{\varepsilon} \sqrt{\frac{2 \ln (b)}{\left(b^{2}-1\right) \Delta t}}$

Em que $\Delta t$ é o intervalo de tempo que se deseja considerar (anual: $\Delta f=1$, mensal: $\Delta t=12$, diário: $\Delta t=365)$.

Na Tabela 2, a seguir, é mostrado um resumo das fórmulas para o cálculo dos parâmetros do MRM:

\subsection{Determinação do processo estocástico mais adequado para simulação dos preços dos combustiveis}

Para determinar o processo estocástico que melhor representa uma variável estocástica, Dixit e Pindyck (1994) sugerem que sejam considerados os aspectos teóricos junto aos resultados de testes estatísticos apropriados. 0 teste que mais tem sido utilizado na bibliografia é o da raiz unitária de Dickey e Fuller (DIAS, 2008).

Para o MRM, o teste da raiz unitária consiste em testar Ho: $b-1=0$, ou seja, testar Ho: $b=1$, em que caso positivo a série terá raiz unitária e seguirá um caminho aleatório, podendo ser modelada de acordo ao MGB, contra $H_{1}$ : $b<1$. Na aplicação do teste de Dickey-Fuller, uma regressão linear é realizada sobre a Equação 12, e logo a seguir é gerada a estatística $\tau$. Se $\tau<$ valor crítico $\Rightarrow \mathrm{H} 0$ é rejeitada. Os valores críticos assintóticos da estatística $\tau$ do teste da raiz unitária de Dickey-Fuller com uma constante e sem tendência temporal são mostrados na Tabela 3.

Quando o teste da raiz unitária é efetuado sobre o preço de ativos financeiros, a hipótese nula da raiz unitária dificilmente é rejeitada, ou seja, a série segue o MGB. Para commodities, Dixit e Pindyck (1994) e

Tabela 2. Resumo das fórmulas de cálculo dos parâmetros do MRM.

\begin{tabular}{cc}
\hline Parâmetro estimado & Equação \\
\hline Velocidade de reversão & $\eta=-\ln (b) / \Delta t$ \\
Volatilidade & $\sigma=\sigma_{\varepsilon} \sqrt{2 \ln (b) /\left[\left(b^{2}-1\right) \Delta t\right]}$ \\
Média de longo prazo & $\bar{x}=\exp [-a /(b-1)]$ \\
\hline
\end{tabular}


Pindyck (1999) só conseguem comprovar que os preços do petróleo não seguem o MGB para uma série de dados de 120 anos (em Pindyck o nível de confiança é de 5\%). Em séries de dados menores, em torno de 30 e 40 anos, os autores não conseguem rejeitar a hipótese nula. No entanto, Bastian-Pinto, Brandão e Alves (2008) e Dias (2008) defendem que, mesmo não sendo rejeitada a hipótese nula, quando obtido $0<b<1$, há indícios de reversão à média. Além disso, fatores estilizados também devem ser considerados na escolha do modelo.

Pindyck (1999) defende o uso do teste da razão da variância como uma alternativa na investigação do modelo a ser seguido por uma série de dados. Esse teste pode ser descrito pela seguinte equação:

$$
R_{k}=\frac{1}{k} \frac{\operatorname{Var}\left(p_{t+k}-p_{t}\right)}{\operatorname{Var}\left(p_{t+1}-p_{t}\right)}
$$

A seguir, a escolha do processo estocástico usado neste estudo na previsão dos preços será realizada através dos dois testes mencionados: o teste da raiz unitária de Dickey-Fuller e o teste da razão da variância sugerido por Pindyck (1999).

0 teste da raiz unitária de Dickey-Fuller é realizado através da análise da estatística $\tau$, calculada com base nos parâmetros obtidos na regressão linear do logaritmo natural da série de preços deflacionados, de acordo à Equação 12. Para o etanol e a gasolina, respectivamente, as equações de regressaõ são as seguintes:

$\ln e_{t}-\ln e_{t-1}=a_{e}+\left(b_{e}-1\right) \ln e_{t-1}+\varepsilon_{t}$

Tabela 3. Valores críticos assintóticos do teste $\tau$ da raiz unitária (Dickey-Fuller) com uma constante e sem tendência temporal.

\begin{tabular}{ccc}
\hline \multirow{2}{*}{$\begin{array}{c}\text { Tamanho da } \\
\text { amostra }\end{array}$} & \multicolumn{2}{c}{ Nivel de confiança } \\
\cline { 2 - 3 } & $1 \%$ & $5 \%$ \\
\hline 50 & $-3,58$ & $-2,93$ \\
100 & $-3,51$ & $-2,89$ \\
250 & $-3,46$ & $-2,88$ \\
$\infty$ & $-3,43$ & $-2,86$ \\
\hline
\end{tabular}

Fonte: Gujarati (2004).

$$
\ln g_{t}-\ln g_{t-1}=a_{g}+\left(b_{g}-1\right) \ln g_{t-1}+\varepsilon_{t}
$$

A regressão foi efetuada usando o software livre Gretl. A estatística $\tau$ do teste de raiz unitária foi gerada pela regressão linear do logaritmo neperiano da série de preços deflacionados. Os resultados com os parâmetros da regressão e a estatística $\tau$ para as diversas regiões geográfica são mostrados na Tabela 4:

Observa-se na Tabela 4 que o valor de $b-1$ para todas as regiões é menor que 1 , o que gera um $b$ positivo tanto para a gasolina quanto para o etanol. A única pergunta é se esses valores são estatisticamente menores que 1 , para que seja comprovado que cada série é estacionária, ou seja, que seguem o MRM.

Se comparados os resultados apresentados na Tabela 4 com os valores críticos assintóticos do teste da raiz unitária com uma constante e sem tendência temporal mostrados na Tabela 3, pode-se observar que a hipótese nula, ou seja, de que existe a raiz unitária, para o nível de 5\% de significância, não é rejeitada para ambos os combustíveis em todas as regiões geográficas. Já que o valor crítico de 2,88 (retornado pela Tabela 3) é menor que todas as estatísticas $\tau$ calculadas, isto é, $\tau>-2,88, \log 0 \mathrm{H}_{\mathrm{o}}$ não é rejeitada, o que indicaria a adequabilidade do MGB. No entanto, a falha na rejeição da raiz unitária não implica na aceitação dela, isso simplesmente deixa a questão em aberto. De acordo com Bastian-Pinto, Brandão e Alves (2008) e Dias (2008), sendo $0<b<1$, a falha na rejeição dessa hipótese não impede a existência do MRM na variável de interesse.

A seguir, a análise será complementada efetuando também o teste da razão da variância (Equação 16), de modo a verificar se o choque entre os preços é temporário ou permanente. Como mencionado, esse teste também foi aplicado por Pindyck (1999), que argumenta que ele é mais informativo que o da raiz unitária.

Os resultados, para a variação dos lags (períodos) de 1 a 60 dos logaritmos neperianos da série de preços deflacionados, podem ser observados nas Figuras $4 \mathrm{e}$ 5 para o etanol e para a gasolina, respectivamente.

\begin{tabular}{|c|c|c|c|c|c|c|c|c|c|c|}
\hline \multirow{2}{*}{ Parâmetro } & \multicolumn{2}{|c|}{ NE } & \multicolumn{2}{|c|}{$\mathrm{N}$} & \multicolumn{2}{|c|}{$\mathrm{CO}$} & \multicolumn{2}{|c|}{ SE } & \multicolumn{2}{|c|}{$\mathrm{S}$} \\
\hline & Etanol & Gas. & Etanol & Gas. & Etanol & Gas. & Etanol & Gas. & Etanol & Gas. \\
\hline$a$ & $-0,001$ & 0,006 & 0,004 & 0,010 & $-0,008$ & 0,010 & $-0,025$ & 0,009 & $-0,009$ & 0,005 \\
\hline$b-1$ & $-0,061$ & $-0,024$ & $-0,045$ & $-0,030$ & $-0,106$ & $-0,031$ & $-0,105$ & $-0,034$ & $-0,096$ & $-0,021$ \\
\hline$b$ & 0,939 & 0,976 & 0,955 & 0,970 & 0,894 & 0,969 & 0,895 & 0,966 & 0,904 & 0,979 \\
\hline$\sigma_{\varepsilon}$ & 0,032 & 0,022 & 0,031 & 0,022 & 0,055 & 0,022 & 0,063 & 0,022 & 0,057 & 0,023 \\
\hline$\tau \operatorname{para}(b-1)$ & $-2,032$ & $-1,098$ & $-1,707$ & $-1,414$ & $-2,648$ & $-1,342$ & $-2,635$ & $-1,645$ & $-2,494$ & $-1,051$ \\
\hline
\end{tabular}

Tabela 4. Resultados da regressão linear para o ln dos preços do etanol e gasolina por região geográfica.

Fonte: Nascimento (2011). 
Pode ser observado na Figura 4 que a razão da variância para o ln do preço deflacionado do etanol decai para 0,16 nas regiões Nordeste e Norte, e para abaixo de 0,06 no Centro-Oeste, Sudeste e Sul com o aumento do lag. Já a razão da variância para o ln do preço deflacionados da gasolina (Figura 5) apresenta uma queda mais lenta, ficando abaixo de 0,23 para as regiões Norte, Centro-Oeste, Sudeste e Sul, e em 0,31 para a região Nordeste quando o lag atinge 60 .

De acordo ao que se observa nas Figuras 4 e 5 , podemos concluir que, para ambos os combustíveis, a razão da variância apresenta uma queda com o aumento o lag, o que é consistente com o modelo no qual o preço é revertido à média (MRM).
Pode-se então supor, com os resultados dos dois testes, de raiz unitária e o de razão da variância, que os preços tanto do etanol quanto da gasolina para as regiões Nordeste (NE), Norte (N) Centro-Oeste (CO), Sudeste (SE) e Sul (S) seguem um processo estacionário (MRM), pois $0<b<1$ e suas razões decaem com o aumento do lag.

Concluindo, pelo comportamento de reversão à média dos preços sugerido pela observação das Figuras 1 e 2, e com base nos testes estatísticos efetuados, neste artigo o MRM com uma constante e sem tendência foi escolhido para modelar os preços do etanol e da gasolina.

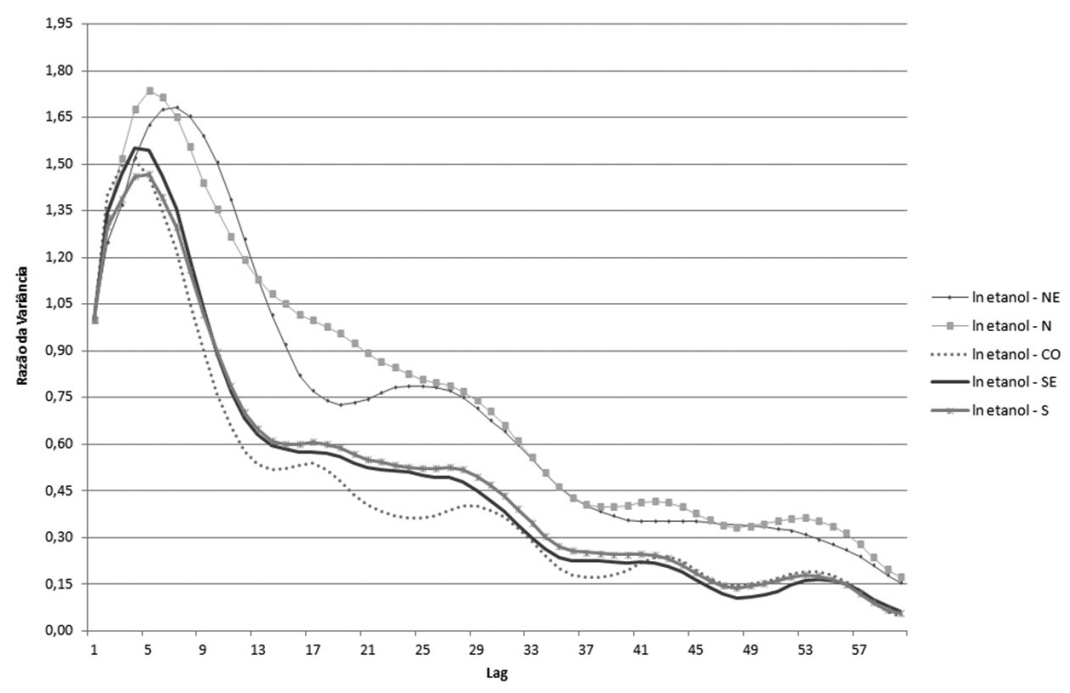

Figura 4. Teste da razão da variância para o ln do preço do etanol por região geográfica.

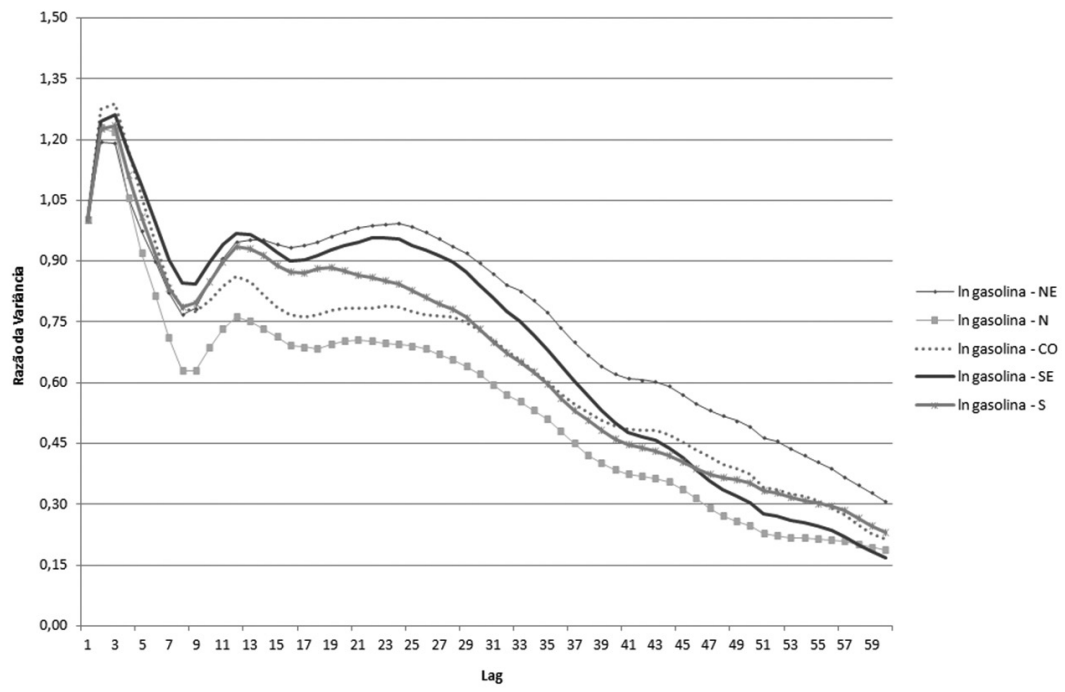

Figura 5. Teste da razão da variância para o ln do preço da gasolina por região geográfica. 


\section{Determinação do valor da opção de troca: premissas, simulação de preços, valoração da opção e apresentação dos resultados}

Tentando respeitar as particularidades e características de cada região do Brasil, neste trabalho será calculada a opção associada ao carro flex-fuel por região geográfica: Nordeste, Norte, Centro-Oeste, Sudeste e Sul. A análise por região geográfica permitirá agrupar os estados com as mesmas características e estabelecer a economia do consumidor de uma forma mais detalhada em comparação a estudos realizados unicamente em âmbito nacional.

\subsection{Premissas usadas nas simulações}

Para efetuar as simulações será necessário estabelecer padrões de consumo por parte do proprietário do veículo flex, assim como definir a vida útil do veículo, a taxa livre de risco e o prêmio de risco a ser utilizado. A versão de carro flex a ser adotado será a dos modelos mais vendidos no mercado brasileiro: VW Gol 1.0 Ecomotion - 2011 flex básico com 2 portas e Fiat Mille Fire Economy 1.0 - 2011 flex básico com 2 portas.

As características desses veículos são mostradas na Tabela 5, que segue:

Como o etanol e a gasolina apresentam diferentes consumos (rendimentos), a Tabela 5 mostra que a relação máxima entre preços (etanol/gasolina) é de 7,4 e 8,9 para o Gol 1.0 e Mille Fire, respectivamente. 0 Centro de Estudos Avançados em Economia Aplicada da USP - CEPEA-USP (2011) estabeleceu que para abastecer com etanol o preço desse combustível

Tabela 5. Características dos veículos selecionados.

\begin{tabular}{lcc}
\hline \multicolumn{1}{c}{$\begin{array}{c}\text { Características } \\
\text { dos veículos }\end{array}$} & $\begin{array}{c}\text { VW Gol 1.0 } \\
\text { Ecomotion } \\
-2011\end{array}$ & $\begin{array}{c}\text { Fiat Mille } \\
\text { Fire Economy } \\
1.0-2011\end{array}$ \\
\hline $\begin{array}{l}\text { Valor do veículo (R\$) } \\
\begin{array}{l}\text { Consumo urbano de gasolina } \\
\text { (km/litro) }\end{array}\end{array}$ & $\mathrm{R} \$ 26.160$ & $\mathrm{R} \$ 23.220$ \\
$\begin{array}{l}\text { Consumo urbano de etanol } \\
\text { (km/litro) }\end{array}$ & 10,5 & 12,7 \\
$\begin{array}{l}\text { Relação máxima entre preços } \\
\text { (etanol/ gasolina) }\end{array}$ & 0,705 & 8,4 \\
$\begin{array}{l}\text { Gasto mensal de gasolina } \\
\text { (litros) }\end{array}$ & 142,86 & 118,11 \\
$\begin{array}{l}\text { Gasto mensal de etanol } \\
\text { (litros) }\end{array}$ & 202,70 & 168,54 \\
Tanque (litros) & 51 & 50 \\
Quilômetros rodados por mês & 1.500 & 1.500 \\
(km) & 72 & 65 \\
Potência máxima gasolina (cv) & 76 & 66 \\
Potência máxima etanol (cv) & 76 \\
\hline
\end{tabular}

Fonte: Inmetro (INSTITUTO..., 2011) e lcarros (2011). deve ser no máximo igual a 70\% do preço do litro da gasolina. Assim, neste estudo, o etanol só será utilizado pelo consumidor quando seu preço por litro for abaixo de $70 \%$ do preço do litro da gasolina.

0 proprietário do carro com a tecnologia flexfuel sempre fará uma escolha ótima no momento do abastecimento, optando pelo combustível que represente o menor fluxo de caixa mensal, de modo a minimizar os gastos durante a vida útil do automóvel. Será suposto, também, para as simulações, que a opção de troca de insumo irá expirar a cada $1.500 \mathrm{~km}$ rodados em um mês. Ou seja, o consumidor escolhe um único combustível em todos os momentos de reabastecimento até que sejam percorridos 1.500 $\mathrm{km}$ em um mês. A decisão de abastecimento no mês i será totalmente independente da decisão do mês j. Assim, o consumidor tem uma série de opções do tipo europeu com sucessivos vencimentos, até o final da vida útil do veículo.

Outros dados necessários nas simulações e no cálculo da opção de troca de combustivel no automóvel flex são os seguintes:

- Vida dos veículos: 5 anos (percorrido em 60 meses $=90.000 \mathrm{~km}$ );

- Taxa livre de risco (r): 6\% a.a (equivalente 0,49\% a.m.);

- Prêmio de risco $(\pi)$ : 6\% a.a. (0,49\% a.m.).

\subsection{Simulação dos preços dos combustíveis}

Aplicando a equação de regressão (Equação 12) para obter os valores dos parâmetros $a, b$ e $\sigma_{\varepsilon}$ (mostrados na Tabela 4), estes são substituídos nas fórmulas resumidas do MRM (mostradas na Tabela 2) para se obter os valores mensais dos parâmetros do MRM (mostrados na Tabela 6), para o etanol e gasolina por região geográfica.

Observa-se na Tabela 6 que o coeficiente de correlação entre as duas séries de preços $\left(\rho_{e, g}\right)$ varia por região na faixa de 0,392-0,496. 0 preço do etanol em todas as regiões reverte mais rapidamente para sua média de longo prazo do que o da gasolina, sendo a volatilidade dos preços da gasolina menor do que a do etanol. Já para a média de longo prazo, destacam-se as regiões Norte e Sudeste, que apresentam para o etanol valores de $\mathrm{R} \$ 1,083 /$ litro e $\mathrm{R} \$$ 0,786/litro respectivamente. Essa diferença, provavelmente, afeta o valor final da opção, quando comparadas as regiões. Ambos os combustíveis apresentam baixa volatilidade (entre 3\% e 7\% para o etanol e em torno de 2\% para a gasolina). Essa baixa volatilidade pode vir a diminuir o preço da opção de troca, pois, conforme apresentado por Kulatilaka (1993), quanto menor a volatilidade dos preços menor será o valor da opção 
Tabela 6. Parâmetros mensais para o MRM modelados para os preços do etanol e da gasolina por região geográfica.

\begin{tabular}{lcccccccccc}
\hline \multirow{2}{*}{ Parâmetro } & \multicolumn{2}{c}{$\mathrm{NE}$} & \multicolumn{2}{c}{$\mathrm{N}$} & \multicolumn{2}{c}{ CO } & \multicolumn{2}{c}{$\mathrm{SE}$} & \multicolumn{2}{c}{$\mathrm{S}$} \\
\cline { 2 - 11 } & Etanol & Gasol. & Etanol & Gasol. & Etanol & Gasol. & Etanol & Gasol. & Etanol & Gasol. \\
\hline Velocidade de reversão & 0,063 & 0,024 & 0,046 & 0,031 & 0,112 & 0,032 & 0,111 & 0,035 & 0,101 & 0,021 \\
Volatilidade & 0,033 & 0,023 & 0,032 & 0,022 & 0,058 & 0,023 & 0,067 & 0,022 & 0,060 & 0,023 \\
Média de longo prazo & 0,986 & 1,293 & 1,083 & 1,384 & 0,930 & 1,362 & 0,786 & 1,285 & 0,915 & 1,277 \\
Correlação $\left(\rho_{\mathrm{eq}}\right)$ & \multicolumn{2}{c}{0,450} & \multicolumn{2}{c}{0,392} & \multicolumn{2}{c}{0,496} & & 0,479 & & 0,492 \\
\hline
\end{tabular}

Fonte: Nascimento (2011).

de troca de combustível. Outros autores como Dias (2008), Bastian-Pinto, Brandão e Alves (2008) e Camargo Jr. et al. (2011) também observaram que a alta correlação entre o preço dos insumos é um fator que diminui o valor da flexibilidade.

Com os valores dos parâmetros do MRM estimados e apresentados na Tabela 6, é possível agora realizar a simulação dos preços dos combustíveis para o período de 60 meses (tempo de vida do automóvel flex neste estudo).

A Equação 8 de discretização, apropriada para uma simulação neutra ao risco, pode ser expressa para o etanol e para a gasolina, respectivemente, pelas Equações 19 e 20.

$$
E_{t}=\ln \left(e_{t-1}\right) \times e^{-0,063 \times 1}+\left[\ln (0,986)-\frac{0,0049}{0,063}\right] \times\left(1-e^{-0,063 \times 1}\right)+0,033 \times \sqrt{\frac{1-e^{-2 \times 0,063 \times 1}}{2 \times 0,063}} N(0,1)
$$

Para o período $t$, para estimar os preços da gasolina $(g)$ e do etanol (e), basta considerar que $x_{t}=\exp \left[X_{t}-0,5 \operatorname{Var}\left(X_{t}\right)\right]$ :

$e_{t}=\exp \left\{E_{t}-0,5\left[\left(1-e^{-2 \eta_{E} t}\right) \sigma_{E}^{2} / 2 \eta_{E}\right]\right\}$

$g_{t}=\exp \left\{G_{t}-0,5\left[\left(1-e^{-2 \eta_{G} t}\right) \sigma_{G}^{2} / 2 \eta_{G}\right]\right\}$

Novamente, tomando como exemplo a região Nordeste, o preço do etanol $\left(e_{t}\right)$ e da gasolina $\left(g_{t}\right)$ é dado por:

$e_{t}=\exp \left\{E_{t}-0,5 \times\left[\left(1-e^{-2 \times 0,063 \times t}\right) \times(0,033)^{2} /(2 \times 0,063)\right]\right\}$

$g_{t}=\exp \left\{E_{t}-0,5 \times\left[\left(1-e^{-2 \times 0,024 \times t}\right) \times(0,023)^{2} /(2 \times 0,024)\right]\right\}$

No processo de simulação dos preços estimados é considerada como inputs a parte estocástica das equações discretizadas (19) e (20), isto é, $N(0,1)$, pois através dela a aleatoriedade é introduzida. No entanto, como os preços dos combustíveis são correlacionados, deve-se incorporar um novo fator estocástico capaz de introduzir essa correlação no modelo de simulação. Para esse fim, é utilizada a chamada decomposição de Cholesky (DIAS, 2008),

$$
\begin{aligned}
& E_{t}=E_{t-1} e^{-\eta_{E} \Delta t}+\left[\bar{E}-\frac{\pi}{\eta_{E}}\right]\left(1-e^{-\eta_{E} \Delta t}\right)+\sigma_{E} \sqrt{\frac{1-e^{-2 \eta_{E} \Delta t}}{2 \eta_{E}}} N(0,1) \\
& G_{t}=G_{t-1} e^{-\eta_{G} \Delta t}+\left[\bar{G}-\frac{\pi}{\eta_{G}}\right]\left(1-e^{-\eta_{G} \Delta t}\right)+\sigma_{G} \sqrt{\frac{1-e^{-2 \eta_{G} \Delta t}}{2 \eta_{G}}} N(0,1)
\end{aligned}
$$

Lembrando que $G_{t}=\ln \left(g_{t}\right)$ e $E_{t}=\ln \left(e_{t}\right)$, pois $g_{t}$ e $e_{t}$ possuem uma distribuição lognormal.

Como ilustração, adotando um prêmio de risco $(\pi)$ de $0,49 \%$ ao mês, e tomando como exemplo a região Nordeste (NE), no período $t$, a equação de discretização para o etanol será dada por:

através da qual um fator estocástico $\left(\varepsilon_{y}\right)$ é gerado e associado a uma das variáveis (etanol ou gasolina). Esse fator é dado pela Equação 23 a seguir:

$\varepsilon_{y}=\rho \varepsilon_{x}+\varepsilon_{w} \sqrt{1-\rho^{2}}$

onde: $\varepsilon_{y}(t) \sim N(0,1) ; \varepsilon_{x}(t) \sim N(0,1) ; E\left[\varepsilon_{y}(t), \varepsilon_{x}(s)\right]=0$ para $t \neq s$.

Neste estudo, esse novo fator estocástico (Equação 23) que incorpora a correlação dos preços foi associado unicamente à variável $E_{t}$ usada na geração dos valores simulados do etanol, mantendo-se $\mathrm{N}(0,1)$ na geração dos valores simulados para a gasolina $(G)$. Ou seja, a Equação 19 foi transformada na Equação 24 abaixo:

$$
E_{t}=E_{t-1} e^{-\eta_{E} \Delta t}+\left[\bar{E}-\frac{(\mu-r)}{\eta_{E}}\right]\left(1-e^{-\eta_{E} \Delta t}\right)+\sigma_{E} \sqrt{\frac{1-e^{-2 \eta_{E} \Delta t}}{2 \eta_{E}}} \varepsilon_{y}
$$

Dessa maneira, a simulação de Monte Carlo sobre os preços dos combustíveis foi efetuada usando as equações discretizadas (20) e (24). Para o processo computacional da simulação dos preços foi usado o software@ @isk ${ }^{\circledR}$ com 10 mil iterações.

Como resultado da simulação, e como ilustração, a Figura 6 mostra para a região Sudeste que a média de longo prazo dos preços simulados do etanol e da gasolina tem um decaimento exponencial com 
o passar do tempo. 0 que pode ser explicado pela tendência de reversão dos preços para sua média de longo prazo (nível de equilíbrio do mercado), decrescido do prêmio de risco normalizado, já que se trata de uma simulação neutra ao risco.

\subsection{Cálculo da opção de troca e análise dos resultados}

Estimados pela simulação dos preços futuros dos combustíveis, agora é possível obter o fluxo de caixa do gasto do proprietário de um automóvel movido exclusivamente a gasolina, ou com motor flex, para os dois modelos de automóveis, VW Gol e Fiat Uno, considerando as características dos veículos dadas na Tabela 5.

0 fluxo de caixa gerado será mensal, tal como a série de preços. Para a geração do fluxo de caixa inicial ( $\mathrm{em} \mathrm{t}=0$ ) é suposto que o consumidor seja indiferente entre o consumo de etanol ou gasolina, pois é mantida em $70 \%$ a relação entre os preços dos combustíveis. Logo, assumindo um valor inicial de $R$ \$2,50/litro para a gasolina, o do etanol será de $\mathrm{R} \$ 1,75 /$ litro $(0,70 \times 2,50)$.

Considerando os gastos mensais com combustível para os dois tipos de veículos (Tabela 5), os demais fluxos de caixa (para $t=1, \ldots, 60$ ) serão determinados como segue:

\section{VW Gol}

Fluxo de caixa para a gasolina: FC_Gol $g_{t}=g_{t} \times 142,86$

Fluxo de caixa para o etanol: FC_Gol $e_{t}=e_{t} \times 202,70$

\section{Fiat Uno}

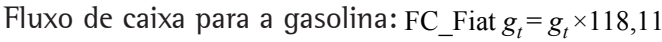

Fluxo de caixa para o etanol: FC_Fiat $e_{t}=e_{t} \times 168,54$
Onde $e_{t}$ é o preço do etanol e $g_{t}$ é o preço da gasolina. A opção de escolha do combustível mais econômico estará associada aos gastos mensais (fluxo de caixa) dos dois tipos de combustíveis, devendo ser escolhido o menor fluxo de caixa, pois isso resultará no menor gasto para o proprietário em cada mês ao longo do tempo de vida útil do veículo.

0 fluxo de caixa $(\mathrm{FC})$ final para cada veículo será dado por:

$\mathrm{FC}$ final_Gol ${ }_{t}=\operatorname{Min}\left(\mathrm{FC} \_\mathrm{Gol} g_{t} ; \mathrm{FC} \_\mathrm{Gol} e_{t}\right)$

FC final_Fiat ${ }_{t}=$ Min $\left(\right.$ FC_Fiat $g_{t} ;$ FC_Fiat $\left.e_{t}\right)$

Por fim, dado que a simulação foi neutra ao risco, para gerar o valor presente dos fluxos de caixa que representam os gastos totais com os veículos flex é usada a taxa livre de risco ( $r=0,49 \%$ a.m.) como fator de desconto, tal como mostrado a seguir:

VP do gasto total do VW Gol $=\sum_{t=1}^{60} \frac{\mathrm{FC} \text { final_Gol }}{t}$

VP do gasto total do Fiat Uno $=\sum_{t=1}^{60} \frac{\text { FC final_Fiat }}{t}$

0 valor da opção de troca de combustível é dado pela diferença entre o valor presente dos gastos totais do automóvel movido somente a gasolina e o valor presente (VP) dos gastos do automóvel flex.

Os resultados, por tipo de veículo e por região geográfica, para o valor presente (VP) dos gastos, para o valor da opção, para a economia de gastos proporcionada pelo veículo flex em relação ao veículo a gasolina e para o valor da opção em relação ao preço de compra do veículo, são mostrados nas Tabelas 7 e 8 . As figuras mostram também as médias desses valores.

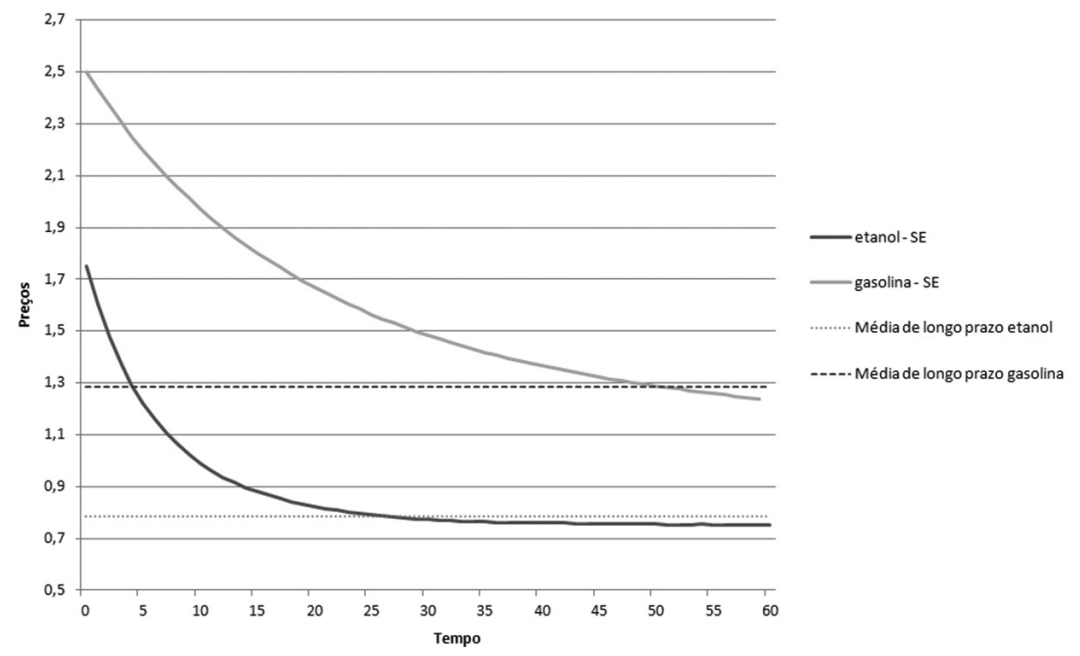

Figura 6. Comportamento da média dos preços simulados dos combustíveis para a região Sudeste. 
Tabela 7. Valor presente (VP) dos gastos, valor da opção, economia de gastos proporcionada pelo veículo flex e valor da opção em relação ao valor de compra do veículo: VW Gol a gasolina ou flex.

\begin{tabular}{|c|c|c|c|c|c|c|}
\hline \multirow{2}{*}{ Valores $(\mathrm{R} \$)$} & \multicolumn{5}{|c|}{ VW GOL } & \multirow{2}{*}{ Média } \\
\hline & $\mathrm{NE}$ & $\mathrm{N}$ & $\mathrm{CO}$ & SE & $S$ & \\
\hline VP veículo só a gasolina & 12.661 & 12.639 & 12.495 & 11.963 & 12.852 & 12.522 \\
\hline .VP veículo flex-fuel & 11.471 & 12.191 & 10.475 & 9.182 & 10.418 & 10.747 \\
\hline .Valor da opção & 1.189 & 448 & 2.020 & 2.781 & 2.434 & 1.774 \\
\hline .Economia (Flex/Gas) & $9,39 \%$ & $3,55 \%$ & $16,17 \%$ & $23,25 \%$ & $18,94 \%$ & $14,26 \%$ \\
\hline .Valor da opção/valor de compra do veículo & $4,55 \%$ & $1,71 \%$ & $7,72 \%$ & $10,63 \%$ & $9,30 \%$ & $6,78 \%$ \\
\hline
\end{tabular}

Tabela 8. Valor presente (VP) dos gastos, valor da opção, economia de gastos proporcionada pelo veículo flex e valor da opção em relação ao valor de compra do veículo: Fiat Uno a gasolina ou flex.

\begin{tabular}{|c|c|c|c|c|c|c|}
\hline \multirow{2}{*}{ Valores $(\mathrm{R} \$)$} & \multicolumn{5}{|c|}{ Fiat Uno } & \multirow{2}{*}{ Média } \\
\hline & $\mathrm{NE}$ & $\mathrm{N}$ & $\mathrm{co}$ & SE & $S$ & \\
\hline .VP veículo só a gasolina & 10.476 & 10.449 & 10.330 & 9.891 & 10.625 & 10.354 \\
\hline .VP veículo flex-fuel & 9.528 & 10.106 & 8.704 & 7.633 & 8.658 & 8.926 \\
\hline .Valor da opção & 939 & 342 & 1.626 & 2.257 & 1.967 & 1.426 \\
\hline .Economia (Flex/Gas) & $8,98 \%$ & $3,28 \%$ & $15,74 \%$ & $22,83 \%$ & $18,51 \%$ & $13,87 \%$ \\
\hline .Valor da opção/valor de compra do veículo & $3,59 \%$ & $1,31 \%$ & $6,22 \%$ & $8,63 \%$ & $7,52 \%$ & $5,45 \%$ \\
\hline
\end{tabular}

Fonte: Nascimento (2011).

As Tabelas 7 e 8 mostram que o valor percentual da opção do veículo flex em relação ao valor de compra varia muito por região geográfica, de um mínimo de 1,31\% para o Fiat Uno na região Norte, a um máximo de 10,63\% para o VW Gol na região Sudeste. As médias nacionais foram $6,78 \%$ e 5,45\% para o VW Gol e Fiat Uno, respectivamente. Comparativamente, o estudo de Camargo Jr. et al. (2011), adotando um MGB e fazendo uma análise para o país como um todo, encontrou uma média nacional entre 10\% e 15\% para um horizonte de projeção de 5 anos.

As Tabelas 7 e 8 mostram que a economia de gastos do veículo flex em relação ao veículo a gasolina oscila grandemente por região geográfica, de um mínimo de 3,28\% para a região Norte, a um máximo de 23,25\% para a região Sudeste. As médias nacionais são de 14,26\% e 13,87\%, para o VW Gol e Fiat Uno, respectivamente. Comparativamente, o estudo de Bastian-Pinto, Brandão e Alves (2008), para o caso do MRM e desconsiderando regionalização, encontrou que a média nacional de economia de gastos do veículo flex em relação ao veículo a gasolina é de 15,55\%. Se bem que este valor é muito próximo às médias nacionais encontradas no presente estudo, o referido artigo não permite observar como essa economia varia grandemente entre as diversas regiões do Brasil.

Como mencionado na introdução, os estudos de Camargo Jr. et al. (2011) e Bastian-Pinto, Brandão e Alves (2008) desconsideraram regionalização e incorporação explícita da correlação dos preços nas equações de simulação, o que foi feito no presente trabalho. 0 primeiro artigo usou séries de preços dos combustíveis no período de julho de 2001 a outubro de 2006, e o segundo no período de julho de 2001 a dezembro de 2009. Já as séries de preços usadas no presente estudo correspondem ao período de julho de 2001 a setembro de 2011, refletindo, de modo mais apropriado, a mudança na relação do preço etanol-gasolina ocorrida no último biênio, o que de fato afetou o valor da opção embutida no veículo flex-fuel.

\section{Conclusões e perspectivas}

A introdução em março de 2003 dos automóveis flex-fuel no mercado brasileiro transformou a forma de escolha do consumidor, que deixou de optar pelo tipo de combustível no momento da compra do automóvel, para optar no momento do abastecimento. Veículos com essa tecnologia são capazes de funcionar com gasolina, etanol hidratado ou qualquer mistura desses dois combustíveis em qualquer proporção. Em 2010 esses veículos representaram mais de $85 \%$ dos veículos comercializados no Brasil.

A flexibilidade proporcionada por esse automóvel ao seu proprietário pode ser entendida como um problema de investimento sob condições de incerteza, sendo adequada a aplicação da abordagem das opções reais para valorar a opção de troca de insumo (switch input option). Para esse tipo de opção, as ações gerenciais são tomadas devido à variação de natureza estocástica dos preços dos insumos, de forma que seja menos custoso e mais lucrativo para o consumidor.

Neste trabalho foi estudado o valor da flexibilidade que o automóvel com tecnologia flex-fuel concede ao seu proprietário no momento do abastecimento, se comparado a um veículo movido somente a gasolina. 0 valor dessa flexibilidade foi calculado por meio da 
abordagem das opções reais, simulando os preços que foram supostos a seguir um MRM. A análise foi feita para cada região geográfica do Brasil, a fim de agrupar características de variação de preços de cada combustível

Os resultados indicam que a opção de escolher o combustível mais barato, entre etanol e gasolina, adiciona valor significativo para o proprietário do automóvel flex em todas as regiões consideradas. A região mais beneficiada pela opção de flexibilidade foi a Sudeste, pois apresentou uma economia entre $22 \%$ e $23 \%$ se comparado a um carro rodando somente a gasolina. Se for considerado o valor do automóvel, o valor da opção representa entre 8\% e $11 \%$ do preço do veículo. A região Norte mostrou-se a menos favorecida dentre as cinco regiões. Nessa região, a opção de flexibilidade apresentou uma economia entre 3,2\% e 3,6\% se comparado a um carro rodando somente a gasolina. Se for considerado o valor do automóvel, o valor da opção representa entre 1,3\% e 1,7\% do preço do veículo.

Os resultados obtidos mostram que o uso do automóvel com tecnologia flex-fuel apresenta não só benefícios ambientais, mas também econômicos para seu proprietário. Os resultados encontrados, somados a outros fatores, podem servir como base para que políticas públicas sejam adotadas, de modo que seja assegurado um mercado competitivo entre o etanol e a gasolina em todas as regiões brasileiras, já que a falta de competitividade pode vir a provocar o consumo de somente um combustível, deixando de ser valiosa a opção de troca de insumo.

Cabe ressaltar que no Brasil atualmente a maioria (85\%) dos veículos comercializados é flex. Em termos de veículos básicos, como os tratados neste estudo, o consumidor quase que não tem mais a possibilidade de adquirir um veículo que não seja flex. Ou seja, na compra do veículo, o consumidor já adquire a opção de troca de combustível, e a exercerá no momento do abastecimento, dependendo da relação de preços dos combustiveis.

\section{Referências}

ASSOCIAÇÃO NACIONAL DOS FABRICANTES DE VEÍCULOS AUTOMOTORES - ANFAVEA. Anuário da indústria automobilística brasileira. 2010. Disponível em: <http:// www.anfavea.com.br/anuario.html>. Acesso em: 10 jan. 2011.

AGÊNCIA NACIONAL DE PETRÓLEO, GÁS NATURAL E BIOCOMBUSTÍVEIS - ANP. Série histórica de preços médios ao consumidor do etanol e gasolina. Disponível em: <http://www.anp.gov.br/preco/prc/Resumo_ Mensal_Index.asp>. Acesso em: 10 out. 2011.

BASTIAN-PINTO, C. L.; BRANDÃO, L. E. T.; ALVES, M. L. The ethanol-gas flex fuel car: What is the option value of choosing your own fuel? In: ANNUAL INTERNATIONAL CONFERENCE ON REAL OPTIONS, 12., 2008, Rio de Janeiro. Proceedings... Rio de Janeiro: PUC-Rio, 2008.
BRASIL. Ministério de Minas e Energia. Lei $n^{\circ}$ 9.478, de 06 de agosto de 1997. Dispõe sobre a política energética nacional, as atividades relativas ao monopólio do petróleo, institui o Conselho Nacional de Política Energética e a Agência Nacional do Petróleo e dá outras providências. Diário Oficial da República Federativa do Brasil, Brasília, DF, 7 ago. 1997. Disponível em: <http:// www.planalto.gov.br/ccivil_03/leis/19478.htm>. Acesso em: 27 ago. 2013.

BESSEMBINDER, $\mathrm{H}$. et al. Mean reversion in equilibrium asset prices: Evidence from the futures term structure. Journal of Finance, v. 50, n. 1, p. 361-375, 1995. http://dx.doi. org/10.1111/j.1540-6261.1995.tb05178.x

CAMARGO JUNIOR, A. S. et al. Option value embedded on the brazilian flex and sustainable vehicles. International Journal of Social Ecology and Sustainable Development, v. 2, n. 3, p. 18-33, 2011. http://dx.doi.org/10.4018/ jsesd.2011070102

CENTRO DE ESTUDOS AVANÇADOS EM ECONOMIA APLICADA - CEPEA. Disponivel em: <http://cepea.esalq. usp.br>. Acesso em: 10 out. 2011.

DIAS, M. A. G. Stochastic processes with focus in petroleum applications. Disponivel em: <http://www.puc-rio.br/ marco.ind/stochast.html\#gbm>. Acesso em: 20 dez. 2008.

DIXIT, A.; PINDYCK, R. Investment under uncertainty. New Jersey: Princeton University Press, 1994

GIBSON, R.; SCHWARTZ, E. S. Stochastic convenience yield and the pricing of oil contingent claims. Journal of Finance, v. 45, n. 4, p. 959-976, 1990 http://dx.doi. org/10.1111/j.1540-6261.1990.tb05114.x

GUJARATI, D. N. Basic econometrics. New York: McGraw-Hill Book Company, 2004.

ICARROS. Catálogo zero quilômetros. Disponível em: <http:// www.icarros.com.br/catalogo/index.jsp>. Acesso em: dez. 2011.

INSTITUTO NACIONAL DE METROLOGIA, NORMALIZAÇÃO E QUALIDADE INDUSTRIAL - INMETRO. Tabela de consumo/eficiência energética de veículos leves. Disponível em: <http://www.inmetro.gov.br/consumidor/ pbe/ veiculos_leves_2011.pdf>. Acesso em: dez. 2011.

KULATILAKA, N. The value of flexibility: The case of a duelfuel industrial steam boiler. Financial Management, v. 33, n. 3, p. 255-240, 1993.

NASCIMENTO, C. C. O valor da opção do carro flex por região geográfica do Brasil: uma aplicação da TOR com MRM. 2011. 117 f. Dissertação (Mestrado)-Pontifícia Universidade Católica do Rio de Janeiro, Rio de Janeiro, 2011.

PINDYCK, R. S. The long run evolution of energy prices. The Energy Journal, v. 20, n. 2, p.1-27, 1999. http://dx.doi. org/10.5547/1SSN0195-6574-EJ-Vol20-No2-1

SCHWARTZ, E. The stochastic behavior of commodity prices: Implications for valuation and hedging. Journal of Finance, v. 52, n. 4, p. 923-973, 1997. http://dx.doi. org/10.1111/j.1540-6261.1997.tb02721.x

SERÔA DA MOTTA, R.; FERREIRA, L. R. The brazilian national Alcohol programme: An economic reappraisal and Adjustments. Energy Economics, v. 10, n. 3, p. 229-234, 1988. http://dx.doi.org/10.1016/0140-9883(88)90007-2

TRIGEORGIS, L. Real options - Managerial flexibility and strategy in resource allocation. Cambridge: MIT Press, 1996. 


\section{Valuation of the switch input option embedded in the Brazilian flex car: a study of a geographical region using a real options approach and stochastic simulation}

\section{Abstract}

The introduction of the flex-fuel car to the Brazilian market in 2003 considerably changed the consumer decision making process. Previously, it was necessary to choose the automobile type, and then the market moved to only gasoline or only sugarcane ethanol; currently, it is possible to choose a car that can run with a combination of these fuels. This flexibility generates economic advantages for the owner, but what are the financial benefits of flex-fuel technology? Geographically, where must the owner be located to have this flexibility? The present paper empirically applies the real options theory to an analysis of the options embedded in the flex-fuel car for five Brazilian geographic regions. The regional price differences and the consumer preferences within these regions were analyzed. For this purpose, historical fuel prices were considered to be stochastic, thus following mean reverting stochastic processes. Price forecasts and option values were generated by Monte Carlo simulation. The results indicated that the option to choose the most inexpensive fuel adds considerable value for the flex-fuel car owner in all regions and car models considered, with the southern region seeing the greatest benefit in the flex option.

Keywords

Real option valuation. Commodity pricing models. Flex-fuel car. Stochastic simulation. 